\title{
Active Learning for Creating Innovators: Employability Skills beyond Industrial Needs
}

\author{
${\text { Hiroshi } \text { Ito }^{1} \& \text { Nobuo Kawazoe }}^{1}$ \\ ${ }^{1}$ Faculty of Economics, Nagoya University of Commerce, Nisshin-shi, Japan \\ Correspondence: Hiroshi Ito, Faculty of Economics, Nagoya University of Commerce and Business, Nisshin-shi, \\ Aichi, Japan. Tel: 81-561-73-2111. E-mail: hito@nucba.ac.jp
}

Received: February 22, 2015

Accepted: March 6, 2015

Online Published: March 12, 2015

doi:10.5430/ijhe.v4n2p81

URL: http://dx.doi.org/10.5430/ijhe.v4n2p81

\begin{abstract}
In 2012, Japan's Ministry of Education, Culture, Sports, Science, and Technology initiated a project entitled "Improving Higher Education for Industrial Needs" in which 147 universities have participated. One of the main purposes of this project is to identify what industrial needs and help develop university students' employability skills through active learning as there has been a growing concern that university graduates lack employability skills that industry seeks. However, Japanese university instructors are unfamiliar with or lack skills for adopting active learning approaches in their courses. This study explores what skills industry needs, examines how these skills can be developed and assessed at university, and describes a course entitled "Business Planning in Practice" that intends to develop these skills through active learning offered at the Nagoya University of Commerce and Business, one of the universities participating in the national project. Business Planning in Practice has been selected as an active learning target course for the Improving Higher Education for Industrial Needs to demonstrate how a university course can employ active learning approaches. The findings show that the skills that industry needs are discovery skills, these skills could be nurtured in the form of research skills at university, and Business Planning in Practice had positive impacts in improving these skills through active learning approaches. This paper concludes with suggestions for how Japanese universities could establish an environment to create innovative human resources.
\end{abstract}

Keywords: Employability, Innovation, Research skills, Industry needs

\section{Introduction}

\subsection{Background}

There is a growing concern that university graduates lack employability skills around the world (Australian Department of Education, 2006; Confederation of British Industry; Rasul, Rauf, Mansor, \& Puvanasvaran, 2012; UNESCO, 2012). In Japan, the Ministry of Economy, Trade, and Industry (METI, 2014) introduced the concept of syakaijin kisoryoku (fundamental competencies for working persons as translated by METI: See Appendix A) in 2006 and the Ministry of Education, Culture, Sports, Science, and Technology (MEXT, 2008) introduced the concept of gakushiryoku (competences expected of university graduates: See Appendix B) in 2008 in an attempt to help develop students' employability skills. In 2009, MEXT started a project called syugyoryoku, which literally means employability skills and provided support for career development including internships, vision planning, and counceling (Kakuhou, Matsumura, \& Hirata, 2011). In 2012, after the turnover and the restructuring of the Japanese government from the Democratic Party to the Liberal Democratic Party, in the same line with syugyoryoku, MEXT initiated another project "Improving Higher Education for Industrial Needs" in which 147 universities have participated. One of the main purposes of this project is to identify what industry needs and to help students develop employability skills through active learning.

As Drew and Mackie (2011) affirm, "one of the most significant underlying reasons offered for the current interest in active learning is as a response to changing economic demands and patterns of work which underpin the ubiquitous discourse of the "learning society" (p. 452). Laverie (2006) also argues that active learning approach "cultivates workplace skills desired by employers: critical thinking, communication skills, leadership skills, creativity, problem solving, task-completion skills and the ability to work in teams" (p. 59). These skills are largely identical with what Wagner (2008), an education expert at Harvard's Innovation Lab, calls seven survival employability skills: 1) critical thinking and problem solving, 2) collaboration across networks and leading by influence, 3) agility and adaptability, 
4) initiative and entrepreneurship, 5) accessing and analyzing information, 6) effective oral and written communication, and 7) curiosity and imagination. Wagner (2012) adds the following attributes to make these skills innovative: a willingness to experiment, take calculated risks, and tolerate failure. The next section explains the term employability and how it is related to innovation.

\subsection{Employability and Innovation}

The term employability can be interpreted in multiple ways. The Confederation of British Industry (2013), for example, defines it as the skills and attributes "that help people respond to the changing demands of the workplace and contribute positively to their employer's success" (p. 4). The Australian Department of Education, Employment, and Workplace Relations (2012) defines it as "the non-technical skills required to effectively participate in the workplace" (p. 2). In the context of Japan, MEXT defines employability as skills necessary for individuals to develop their aptitudes and to become socially and professionally independent (Ito, 2014a).

According to Dyer, Gregersen, and Christensen (2011), there exist two types of employability skills: delivery and discovery skills. Delivery skills are analyzing, planning, detail-oriented, implementing, and disciplined executing while discovery skills are associating, questioning, observing, networking, and experimenting that Dyer et al. (2011) consider essential for creating innovators. Both skills are considered necessary for any organization to function or innovate itself. They argue, however, that what most companies lack is human resources with discovery skills as there are few with these skills but any company will die out ten years from now without innovators (Dyer et al., 2011). As is the case with the term employability, innovation can be defined in many different ways. Harada (2010), for example, explains that innovation is value creation through the introduction of new technology, thinking, and business models. O'Sullivan (2008) defines the term as "the process of making changes to something established by introducing something new" (p. 3). The International Fund for Agricultural Development (IFAD, 2007) defines it as "a process that adds value or solves a problem in new ways" (p. 4).

Many Japanese companies used to be considered innovative around the globe but may no longer be so as they have been transformed into more delivery- than discovery-oriented due to their lack of innovative skills (O'Gorman, 2012). Indeed, while BusinessWeek's ranking of innovative companies "based on past performance" (Dyer et al., 2011, p. 4) has constantly placed Japanese companies such as Toyota, Sony, and Nintendo in the top 20 list (BusinessWeek, 2010), Forbs' ranking of the world's most innovative companies measured by the innovative premium, which are decided on the votes from investors who are asked which companies are innovative today and future (Dyer et al., 2011), lists none of them even in the top 50 ranking (Forbes, 2014).

According to Harada (2010), many Japanese companies had originally been openly innovative: it is not that they invented something totally new but improved exisiting technologies from the West for production and sales. That improvement part (between Western technologies and products for sale) was Japanese value-added open innovation. As Harada (2010) explains, however, Japanese companies were criticized as free riders by the West (because they "stole" technologies from them) in the 1980s and were urged to reinforce their own R\&D. Yet, many Japanese companies could not cope with the change. There exist several possible reasons that Japanese companies were not successful in reinnovating themselves, such as the large scale of Japanese companies, a lack of governmental support to venture capitals, and clingness to old-fashioned ways of open innovation that brought them success. The Bubble economy might also have impaired innovation as companies were more into investments in stockmarket and land property rather than R\&D. Among them, some scholars argue that Japanese culture and education are culprits.

For instance, O'Gorman (2012) argues that the Japanese may culturally be opt to be more delivery-oriented than, for example, the US companies as Japanese companies tend to take fewer risks (Fitzpatrick, 2013). McVeigh (2002) points out that the fact that Japanese tend not to possess discovery skills or do not take risks for innovation may be attributed to Japanese education that requires students to be passive and submissive. In Japanese higher education, he analyzes "one of the most important lessons students do learn: hierarchy as expressed in junior/senior relations essential for being a sunao (obedient) worker" (McVeigh, 2002, p. 215). It is in this context that active learning, which potentially enables students to be proactive, started drawing attention in Japan.

While both discovery and delivery skills can be considered employability skills, creating discovery-oriented innovators is a much more difficult task than finding or training delivery-oriented employees and this may be even more so in the context of Japan as the Japanese may not be encouraged to be innovative (Nonaka and Takeuchi, 1995) in part due to its cultural characteristics (O'Gorman, 2012). Yet, as Wagner (2012) argues, "only the jobs of innovators and entrepreneurs will be immune to outsourcing or automation in the new global knowledge economy" (xiv). That is to say, discovery skills are virtually the only employability skills that work universally in the current and the future society. 
Having interviewed over 200 innovators, Wagner (2012) noticed that many of his informants used the term "creative" or "creativity" to express innovation. As he states, "[w]e can substitute the word innovation for creativity [with value]" (p. 22). This statement is echoed by Cobo (2013, p. 68) that "[s]kills for innovation comprise creativity" as well as others such as communication, adaptability, and entrepreneurial and trans-disciplinary competencies communication." Cokpekin and Knudsen (2012, p. 304) also affirm that "[c]reativity has been widely accepted as a key ingredient of innovation." Wagner (2012) argues that "[t]he capacity for creativity is the result of an interrelationship among three things: expertise, creative-thinking skills, and motivation" (p. 22). Although univeristies have traditionally focused on teaching expertise, Teresa Amabile, a professor of Harvard Business School, believes that motivation is "far more important than either expertise or skills...motivation determines what people will actually do" (as cited in Wagner, 2012, p. 23). Wagner (2012) also argues for the significance of creative-thinking skills for innovation: "to ask right questions, make connections, observe, empathize, collaborate, and experiment" (p. 23). With an exception of empathy, these skills/attributes exactly overlap with skills that Dyer et al. (2011) consider essential for innovation (i.e., associating, questioning, observing, networking, and experimenting).

While there is "no concerted effort to nurture the creativity of all children" (Wagner, 2012, p. 7), some scholars argue that active learning motivates and enables students to be more creative (Peters, 2008). What creative and innovative skills should and could be nurtured at university? One of the possible answers is research skills, which overlap with syakaijin kisoryoku in some respects but more discovery-oriented than delivery-oriented (see Figure 1).

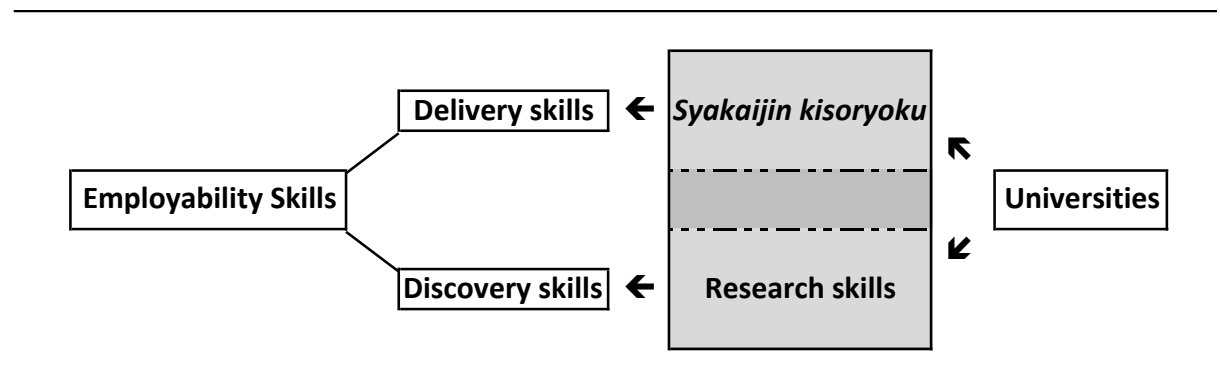

Figure 1. Skills that universities should develop for employability

While syakaijin kisoryoku is associated with a certain image of how "working persons" should be (METI, 2014) and often what delivery-oriented companies seek (e.g., individuals with discipline, stress control, and common senses), the purpose of nurturing research skills and conducting research is to find something new, usually based on but different from previous research.

As Forsyth (2007) explains, research skills serve for innovation as it "requires new data or new analytical techniques" (p. 461) and "relies on good information, clear theories and a multi-dimensional view of the public interest. There is a strong line with research" (p. 464). He continues that universities "have some advantages in creating innovative contexts, enabling the conduct of research that combines convergent and divergent thinking and sparks transferable solutions" (p. 467).

This paper suggests that these research skills for innovation be better nurtured through courses with active learning approaches. According to Ito (2014a)'s study, however, many Japanese university instructors are unfamiliar with or lack skills for employing active learning in their courses in part because they themselves were not educated in the active learning environment. The next section reviews active learning and its issues followed by the description of a course called Business Planning in Practice, which intends to develop research-related skills through active learning, offered at the Nagoya University of Commerce and Business (NUCB) in Japan.

\subsection{Active Learning}

As Drew and Mackie (2011) state, active learning lacks a universal definition. While Greene (2011) defines active learning as learning by doing based on hands-on experience, Ernst (2011, p. 24) argues that active learning motivates "students to participate mentally, by whatever method works." Agbatogun (2014) also describes active learning as "anything course-related that all students in a class session are called to do other than simply watching, listening and taking notes" (p. 259). Given Ernst's and/or Agbatogun's statements, as long as students are engaged with learning, even lectures and reading/writing tasks can be part of active learning processes (Benson \& Hwang, 1995; Gier, 
Herring, Hudnell, Montoya, \& Kreiner, 2010; McWhorter, 2012). Active learning is, however, often comprised of cooperative and/or problem/project-based learning (PBL) (Enriquez, 2013; Herrmann, 2013; Laverie, 2006; L'Allier \& Elish-Piper, 2007; Prince, 2004; Walker, 2005; Wu, Wang, Spector, \& Yang, 2013; Yoder \& Hochevar, 2005).

As Perez, Garcia, Muñez, Alonso and Puche (2010) explain, "[c]ooperative learning is the instructional use of small groups so that students work together to maximize their own and each other's learning" (p.1). Despite some drawbacks, such as free riders and dependence on peers (Hall \& Buzwell, 2013; Joyce, 1999), there is a general consensus that cooperative learning motivates students to engage with learning (Ito, 2014b; Koohang \& Paliszkiewicz, 2013), enhances academic performances (Rutherford, 2012; Kawaijuku, 2014), and provides students with opportunities to work in real world situations (Hall \& Buzwell, 2012).

PBL entails similar benefits to cooperative learning: students analyze real problems, work in groups, and develop research skills. For instance, Gokhan (2013) discusses that PBL involves students in conducting research and solving problems in a socially interactive environment. Hopper (2014) also states that "[a]uthentic PBL can improve the development of problem solving, higher-order thinking, and research skills in students" (p. 79). Therefore, employing active learning approaches such as cooperative learning and/or PBL is reasonable to help develop studens' research skills, especially in the employability context, as students work on real world issues.

One of the major challenges of employing active leaning approaches is that teachers may have more difficulty in managing the course than conventional teaching approaches as they let students take more control for them to be proactive. As Drew and Mackie (2011) explain, "active learning is potentially problematic for teachers since it appears to position them in a more sidelined teaching role than they are accustomed to: although they are central to negotiating and enacting active learning spaces, they no longer hold center stage" (p. 459). For students to act properly on the stage, teachers may also have to spend more energy and time for preparation and assessment outside of the classroom (Peters, 2011).

Another challenge of employing active learning is that "students' rate of progress may be slower because the amount of knowledge flow from teachers to students may be limited as active learning approaches consume more time than stimulus-response/passive learning" (Peters, 2011, p. 467). Active learning, howerver, has potential to lead to deeper understanding (Drew \& Mackie, 2011). The following section describes a university course that intends to help students develop research-related skills through active learning and assess the improvement in students' research skills before and after the intervention (i.e, at the beginning of the course and the end of the course).

\subsection{Business Planning in Practice}

Despite its potential and increasing popularity, many Japanese university instructors seem to struggle to emply active learning in their courses (Ito, 2014a). This setion describes a course intending to develop research-related skills called Business Planning in Practice at NUCB. This has been selected as an active learning target course in the national project titled "Improving Higher Education for Industrial Needs" in order to demonstrate how a university course can employ active learning approaches, which will be shared by participating universities in the end of the project.

Business Planning in Practice is a semester-long course, which targets third and fourth year students and 45 students registered in the 2014 Spring semester. The length of the course is fourtheen 100-minute weekly sessions. This course is expected to serve as an intermediate course before Developing NUCB Frontier Skills and Attributes (an advanced course). In this course, students learn about Toyota City's eco-policies, conduct survey research about the citizen's recognition of the city's eco-policy, analyze the collected data, and make possible suggestions. In this course, students acquire research-related skills through active learning approaches as follows: 1) lectures with Q\&A sessions given by personnel from Toyota City Hall about Toyota City's eco-policies, Japan Touristic Bureau (JTB) about public marketing, and the United Nations Center for Regional Development (UNCRD) about sustainable development at the macro level; 2) cooperative learning that students work in groups such as preparing and performing group presentations and creating survey and exam questions together; 3) PBL through conducting research on Toyota citizens' eco-awareness and promoting the city's eco-policy; and 4) reading and writing through literature review and data analysis reports, as detailed in the course outline (Appendix C).

\section{Method}

\subsection{Selection of Participants}

In this study, 28 students who took the course entitled Business Planning in Practice offered at NUCB were selected as participants. NUCB is one of the 147 universities that have participated in a national project entitled Improving Higher Education for Industrial Needs. It is a limitation of this study that the number of participants is small and 
participants were selected from one specific university. Nonetheless, NUCB is an average university among the 147 universities in terms of the size of its student body and academic level. The number of NUCB students is approximately 3,500, which is close to the average number of students per Japanese university (Statistics Bureau of Japan, 2014). Also, Japanese universities are often ranked according to what is known as the standard score (scaled to mean of 50; $z=\chi-\mu / \alpha$ ). NUCB is ranked in the standard deviation of 45 . While it is difficult to calculate the average standard score of all 147 universitites as the rating can depend on majors as well as agencies publishing the data, according to the Yoyogi Seminar (2015), one of the largest prep schools in Japan, the majority of the 147 universities fall into the standard deviation of 40-50. Thus, the selected participants from NUCB may be representative of students at the 147 universities. Although 45 students registered for Business Planning in Practice, only 28 were selected for this study because they were the ones who attended the course over $80 \%$ of the time (i. e., more than 11 out of the total 14 sessions).

\subsection{Assessment of Research Skills}

Assessment of students' research-related skills is twofold: assessments by students and by the instructor. Peers were also involved in grading group presentations, but they did not specifically evaluate research skills and thus their contribution is not taken into account here. Students self-assess the improvement of their research-related skills at the beginning of the course and the end of the course, using 5 Likert evaluation sheets to measure shakaijin kisoryoku enacted by METI. Howerver, only research-related skills and attributes were extracted from twelve syakaijin kisoryoku to be assessed. These research-related skills are: 1) Agility, adaptability, and initiative, 2) Willingness to experiment and take risks, 3) Teamwork/collaboration skills, 4) Problem solving skills, 5) Analytical reasoning/critical thinking skills, 6) Curiosity and imagination, and 7) Written communication skills. Students graded their research-related skills from strongest " 5 " to weakest "1." The mean difference of these scores and the results of a paired sample t-test to examine statistical significance of the results are tabled (Table 1) in the following section.

The instructor also assessed the improvement of students' research-related skills at the beginning of the course and the end of the course, comparing the qualities of their reports about relevant literature review with those of their analysis reports on the research data. For this purpose, the ICE rubric, a qualitative learning assessment tool developed by Young and Wilson (2000), was employed. "I" of ICE refers to Idea, "C" refers to Connection and "E" refers to Extension. Ideas refer to knowledge and information essential for new learning. Connections are divided into two different levels: the content level and the personal meaning-making level. Students at the content level are able to identify relationships among different ideas. Students at the personal meaning-making level are able to relate their knowledge to new learning. Extension is the application of knowledge in different contexts. For instance, a student's work proposing concrete solutions to a newly encountered problem may be considered in the "E" stage. Given that Business Planning in Practice may be positioned as an intermediate course toward Developing NUCB Frontier Skills, a more advanced course, this course is expected to bring the level of students to the "C" stage.

\section{Results}

Table 1. Assessment of research skills (One-sample t-test)

\begin{tabular}{lccc}
\hline \multicolumn{1}{c}{ Item: Skills and attributes } & Mean & Std. Err. & P-value \\
\hline 1 Agility, adaptability, and initiative & 0.250 & 0.132 & 0.035 \\
2 Willingness to experiment and take risks & 0.071 & 0.162 & 0.332 \\
3 Team work/collaboration skills & 0.143 & 0.151 & 0.178 \\
4 Problem solving skills & 0.250 & 0.167 & 0.074 \\
5 Analytical/critical thinking skills & 0.000 & 0.178 & 0.500 \\
6 Curiosity and imagination & 0.214 & 0.149 & 0.081 \\
7 Written communication skills & 0.214 & 0.149 & 0.081 \\
\hline
\end{tabular}

The results indicate that all research-related skills and attributes except for analytical and critical thinking skills showed a sign of improvement. The paired t-test shows that the improvement of Item 1 (agility, adaptability, and initiative) was statistically significant at the .05 level and improvements of Item 4 (problem solving skills), Item 6 (curiosity and imagination), and Item 7 (written communication skills) were statistically significant at the .10 level.

Also, at the beginning of the course, the quality of reports for literature review remained in the "I" stage of the ICE assessment model: students merely described factual information drawn from literature without any description of their analysis or critique of the literature. Several analysis reports after the survey research, however, reached at least the "C" or even the "E" stage. Given that some items in Toyota City's eco-policy were not well recognized, students made suggestions to further raise the Toyota City's citizen's awarenss of its eco-policy. Below are such examples: 
Items with lower recognition rate should be promoted: for example, the venders of the Toyota Motor Corporation could place flyers stating "Toyota is an environmental model city. Would you also contribute to environmental protection?" in their car dealer shops and encourage the purchase of electric or plug-in hybrid vehicles.

This part is rated " $\mathrm{C}$ " because the student analyzed the problem and proposed a solution, but did not mention how it could be done. While Toyota Motor Cooperation has been a key player in promoting Toyota City's eco-policy, it is unfeasible for Toyota City to do the suggested task.

If school children are given homework that they do research on Toyota City's eco-policy and go to Ecoful Town together with their parents and siblings, not only children but also adults might be interested in its eco-related items.

The level of the student's report may lies somewehere between "C" and "E" stages. While it does not seem new and Toyota City actually already does something similar (all fourth graders at the primary level in the city visit Ecoful Town before summer break as a social study tour), the student suggestion is concrete and feasible. To bring the level of her report to the complete "E" level may require the content of the assignment during and after the visit to Ecoful Town.

\section{Discussion}

This paper discussed that the universal employability skills are discovery/innovative skills, one of which to be developed at university is research skills. This paper then examined how Business Planning in Practice possibly helped students improve research-related skills. The results from the syakaijin kisoryoku evaluation sheet (items related to research skills) and the ICE assessment model show that students have improved some of these skills and attributes, notably agility, adaptability, and initiative. At the same time, critical thinking and analytical reasoning skills, which are arguably most important research skills, did not improve at all, which remains an issue to be addressed. Obviously, what can be done in a single course is limited. Developing research skills requires institutional efforts.

One of the universities specialized in creating innovators through developing research skills is Olin, an American engineering school with liberal arts elements located in Massachusetts (Wagner, 2012). While there are very diverse courses from arts to business, the university requires students to integrate content from different courses "to create a final product and to actively think about how their work in one class relates to work they've done in other classes" (Wagner, 2012, p. 175). Almost every course, if not all, has the components of creative problem solving based on team projects and students select courses that they find interesting and/or useful to develop their ideas into connection and/or extension, for example, in the ICE framework. As Wagner (2012) explains, Olin students are provided with opportunities "to pursue their own interests and to discover their passion and so move toward a deeper sense of purpose" (p. 177).

It is difficult, however, especially for Japanese universities, to follow the Olin model in part due to the difference of curricula. In Japan, typical university students take about ten 90-minute two-credit courses per semester while their US counterparts take three to four 180-minute three- or four-credit courses per quarter or per semester. Japanese instructors have (more) difficulty in realizing PBL due to time constraints. Japanese instructors also have to take the workload of their students into account as Japanese students theorethically spare only one-tenth or less of their studying time for the course that they teach. Also, many Japanese courses exist without mutual relevances; hence, the ideas and knowledges that Japanese university students acquire in different - while seemingly diverse - courses are not connected to each other without further extension and/or development. Since Japanese university students take ten or more courses that are often irrelevant to each other per semeseter, their learning tend to remain superficial while US university students can concentrate on fewer and more relevant courses and take deep approach to learning. In order to enable Japanese university students to take deep approach to learning, the following is suggested: 1) to reduce the number of couses to be taken per semester from the current ten to four or five and augment credit hours from the current two to four. Accordingly, one course session hours change from the current 90 minutes to 180 minutes (or two 90 minute sessions a week). If students take four four-credit courses per semester, they can obtain 32 credits per year or 128 credits for four years. Those who would like to finish their course work before the fourth year can take five four-credit courses per semester. Some may be worried that reducing the number of courses is reducing studying time; however, there is a general concensus that US university students study much harder and deeper than Japanese students (Tsuji, 2013) despite fewer courses taken; and 2) to make courses more relevant to each other. For instance, Business Planning in Practice was originally positioned as an intermediate course after "Introduction to Regional Planning" (an introductory course) and before "Developing NUCB Frontier Skills and Attributes" (an 
advanced course). Students already have certain knowledges of and familiarity with regional issues, including those of Toyota City by the time they take Business Planning in Practice. It is more likely that they can smoothly connect and apply the basic knowledge acquired in Introduction to Regional Planning to the current and future learning, including Developing NUCB Frontier Skills and Attributes. Ideally, all courses should be relevant to some others with a basic-intermediate-advanced structure and/or numbering (e.g., Statistics 101A, 101B, 101C, 102A, 102B, 102C). This way, ideas can be reinfonced to be connected and developed into extension, leading eventually to innovation. MEXT as well as universities need to address these issues as the creation of innovative human resources will help future development of the country.

\section{References}

Agbatogun, A. D. (2014). Developing learners' second language communicative competence through active learning: Clickers or communicative approach? Educational Technology \& Society 17(2): 257-269.

Australian Department of Education. (2006). Enployability skills: From framework to practice. Australian Government.

Benson, J. \& Hwang, Y. (1995). Thinking about methodology: Student initiated active learning in reading and writing. Education 115(4): 493-499.

Businessweek. (2010). The 25 most innovative companies 2010. Available at: http://images.businessweek.com/ss/10/04/0415_most_innovative_companies/index.htm?technology+slideshows

Cobo, C. (2013). Skills for innovation: envisioning an education that prepares for the changing world. The Curriculum Journal 24(1): 67-85. http://dx.doi.org/10.1080/09585176.2012.744330

Cokpekin, Ö. \& Knudsen, M. (2012). Does organizational creativity really lead to innovation? Creativity and Innovation Management 21(3): 304-314. http://dx.doi.org/10.1111/j.1467-8691.2012.00649.x

Confederation of British Industry. (2009). Future fits: Preparing graduates for the world work. Available at: http://www.cbi.org.uk/media/1121435/cbi_uuk_future_fit.pdf

Department of Education, Employment, and Workplace Relations. (2012). Employability skills Framework stage 1 final report. Toowong, QLD: Ithaca Group.

Drew, V. \& Mackie, L. (2011). Extending the constructs of active learning: implications for teachers' pedagogy and practice. The Curriculum Journal 22(4): 451-467. http://dx.doi.org/10.1080/09585176.2011.627204

Dyer, J., Gregersen, H., \& Christensen, C. M. (2011). The innovator's DNA: Mastering the five skills of disruptive innovators. Boston: Harvard Business Review Press.

Enriquez, G. (2013). 'But they won't let you read!': A case study of an urban middle school male's response to school reading. Journal of Education 193(1): 35-46.

Ernst, M. (2011). Active learning? Not with my syllabus! Teaching Statistics Trust 34(1): 21-24. http://dx.doi.org/10.1111/j.1467-9639.2010.00454.x

Fitzpatrick, M. (2013). Can Japan reboot its anti-innovation start-up culture? Available at: http://www.bbc.com/future/story/20130820-plugging-japans-start-up-gap

Forbes. (2014). The world's most innovative companies list. Available at: http://www.forbes.com/innovative-companies/list/

Forsyth, A. (2007). Innovation in urban design: Does research help? Journal of Urban Design 12(3): 461-473. http://dx.doi.org/10.1080/13574800701602569

Gier, V. S., Herring, D., Hudnell, J., Montoya, J., \& Kreiner, D. S. (2010). Active reading procedures for moderating the effects of poor highlighting. Reading Psychology 31: 69-81. http://dx.doi.org/10.1080/02702710903397082

Gokhan, A. (2013). The effect of project-based learning on students' motivation. International Journal of Academic Research 5(2): 82-86. http://dx.doi.org/10.7813/2075-4124.2013/5-2/B.11

Greene, H. (2011) Freshmen marketing: A first-year experience with experiential learning. Marketing Education Review 21(1): 79-87. http://dx.doi.org/10.2753/MER1052-8008210111

Hall, D. \& Buzwell, S. (2013). The problem of free-riding in group projects: Looking beyond social loafing as reason for non-contribution. Active Learning in Higher Education 14(1): 37-49. http://dx.doi.org/10.1177/1469787412467123 
Harada, I. (2010). Tayouna jyouhousyakai ni okeru daikigyou no inobeesyon (Innovation in large companies in diverse knowledge societies to provide a unique open innovation model). Jounal of Informational Sociology 5(2): $29-40$.

Herrmann, K. J. (2013). The impact of cooperative learning on student engagement: Results from an intervention. Active Learning in Higher Education 14(3): 75-87. http://dx.doi.org/10.1177/1469787413498035

Hopper, S. B. (2014). Bringing the world to the classroom through videoconferencing and project-based learning. TechTrends May/June 58(3): 78-88.

IFAD. (2007). Innovation strategy. Rome: IFAD.

Ito, H. (2014a). Challenges towards employability: Higher education's engagement to industrial needs in Japan. Higher Education Studies 4(2): 1-8. http://dx.doi.org/10.5539/hes.v4n2p1

Ito, H. (2014b). What's wrong with learning for the exam? An assessment-based approach for student engagement. Journal of Education and Learning 3(2): 135-144. http://dx.doi.org/10.5539/jel.v3n2p145

Joyce, W. B. (1999). On the free-rider problem in cooperative learning. Journal of Education for Business 74(5): 271-274. http://dx.doi.org/10.1080/08832329909601696

Kakuhou, M., Matsumura, N., \& Hirata, F. (2011). Syungyouryoku to daigaku kaikaku (Employability skills and the higher education reform). Tokyo: Gakuji Syuppan.

Kawaijuku. (2014). Manabi no shitsu wo hosyousuru akutibu laaningu (Active learning for the assurance of learning). Tokyo: Toshindo.

Koohang, A. \& Paliszkiewicz, J. (2013). Knowledge construction in e-learning: An empirical validation of an active learning model. Journal of Computer Information Systems 53(3): 109-114.

Laverie, D. A. (2006). In-class active cooperative learning: A way to build knowledge and skills in marketing course. Marketing Education Review 16(2): 59-70.

L'Allier, S. K. \& Elish-Piper, L. (2007). 'Walking the walk' with teacher education candidates: Strategies for promoting active engagement with assigned readings. Journal of Adolescent \& Adult Literacy 50(5): 338-353. http://dx.doi.org/10.1598/JAAL.50.5.2

McVeigh, B. J. (2002). Japanese higher education as myth. New York and London: An East Gate Book.

McWhorter, K. T. (2012). Active reading skills: Reading and critical thinking in college. Reading, MA: Addison Wesley.

Ministry of Economy, Trade, and Industry (METI). (2014). Syakaijin kisoryoku (Fundamental competencies for working persons). Available at: www.meti.go.jp/policy/kisoryoku/about.htm

Ministry of Education, Culture, Sports, Science, and Technology (MEXT). (2008). Gakushiryoku (Skills for university graduates). Available at: http://www.mext.go.jp/b_menu/shingi/gijyutu/gijyutu4/siryo/attach/ 1247211.htm

Nonaka, I. \& Takeuchi, H. (1995). Knowledge-creating company: How Japanese companies create the dynamics of innovation. New York and Oxford: Oxford University Press.

O'Gorman, D. (2012). What Japanese companies must do to create a second economic miracle? Available at: http://iveybusinessjournal.com/topics/innovation/what-japanese-companies-must-do-to-create-a-second-econom ic-miracle\#.U7O9_HCXJ_M

O’Sullivan, D. (2008). Applying innovation. Thousand Oaks, CA: Sage Publishing.

Perez, J. E., Garcia, J., Muñez, I., Alonso, A. S., \& Puche, P. L. (2010). Cooperative learning vs. project based learning: A practical case. IEEE EDUCON Education Engineering 2010. The Future of Global Learning Engineering Education April 14-16, 2009, Madrid, Spain.

Peters, K. (2008). What is meant by 'active learning?' Education 128(4): 566-569.

Peters, R. A. (2011). Enhancing academic achievement by identifying and minimizing the impediments to active learning. Public Administration Quarterly 35(4): 466-493.

Prince, M. (2004). Does active learning work? A review of the research. Journal of Engineering Education 93(3): 223-231. http://dx.doi.org/10.1002/j.2168-9830.2004.tb00809.x 
Rasul, M., Rauf, R. A., Mansor, A. N., \& Puvanasvaran, A. P. (2012). Employability skills assessment tool development. International Studies 5(5): 43-56.

Rutherford, P. (2012). Active learning and engagement strategies. Alexandria: Just ASK Publications \& Professional Development.

Statistics Bureau of Japan. (2014). Tankidaigaku to daigaku no nyuugakusya su. The number of junior college and university entrants. Available at: http://www.stat.go.jp/data/nihon/22.htm

Tsuji, T. (2013). Naze nihon no daigakusei wa sekai de ichiban benkyou shinai no ka (Why do Japanese university students study the least in the world?). Tokyo: Toyo-keizai shinpou sya.

UNESCO. (2012). Graduate employability in Asia. UNESCO Bangkok.

Wagner, T. (2008). The global achievement gap. New York: Basic Books.

Wagner, T. (2012). Creating innovators: The making of your people who will change the world. New York: Scribner.

Walker, B. J. (2005). Thinking aloud: Struggling readers often require more than a model. The Reading Teacher 58(7): 688-692. http://dx.doi.org/10.1598/RT.58.7.10

Wu, B., Wang, M., Spector, J. M., \& Yang, S. J. H. (2013). Design of a dual-mapping learning approach for problem solving and knowledge construction in ill-structure domains. Educational Technology \& Society 16(4), 71-84.

Yoder, J. D. \& Hochevar, C. M. (2005). Encouraging active learning can improve students' performance on examinations. Teaching of Psychology 32(2): 91-95. http://dx.doi.org/10.1207/s15328023top3202_2

Young, S. F. \& Wilson, R. J. (2000). Assessment \& Learning: The ICE Approach. Winnipeg: Peguis Publishers.

Yoyogi Seminar. (2015). Nyuushi nanido ranking (University ranking). Available at: http://www.yozemi.ac.jp/rank/gakka/

\section{Appendix A: Fundamental competencies for working persons by METI}

\section{< 3 Competencies / 12 Competency Factors >}

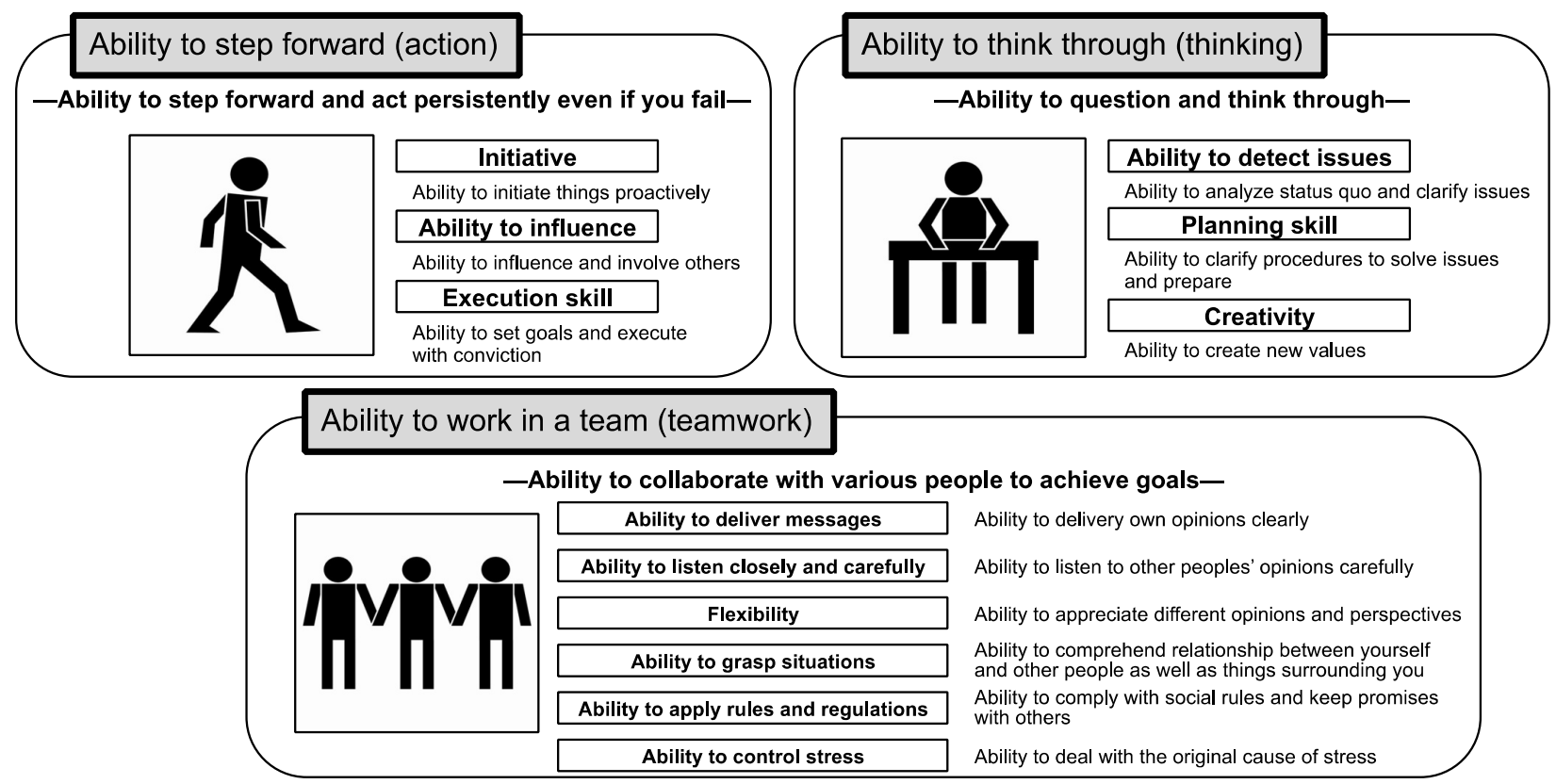




\section{Appendix B: University graduates' expected competencies according to MEXT}

- Knowledge: Mastering basic knowledge in one's major field of study, understanding foreign cultures, current social affairs, nature, and one's own culture

- Skills: Communication Skills (reading, writing, listening, and speaking in Japanese as well as in a given foreign language), Information Utilization Skills (proper application of various information acquired through the Internet or other sources for a given purpose), and Logical Thinking Ability

- Attitudes: Team Work, Leadership, Moral Values, Lifelong Learning Ability

- Creative Thinking Skills

\section{Appendix C: Course outline for Business Planning in Practice}

\section{Week 1: Introduction}

Students are provided with a description of the course, briefed about Toyota City's eco-policies, and divided into five teams focused on each core theme related to the city's eco-policies: transportation, forestry, industry, urban centers, and public welfare and livelihood. Students prepare introductory presentations on their team's theme to be presented during the second week. At this point, evaluation sheets are provided to students so that they can self-assess their research skills so that their research performance can be examined for signs of improvement following course completion.

\section{Week 2: Toyota City's environmental policies}

Each team gives a presentation about their assigned theme. The presentations are peer-reviewed with evaluation sheets that will be delivered to students. The instructor assesses and grades the quality of the peer-reviewed evaluation sheets (e.g., based on whether students provided comments and/or feedback). It is expected that students provide constructive feedback for their peers.

\section{Week 3: Guest lecture: Personnel from Toyota City Hall}

Personnel from Toyota City Hall give a lecture about Toyota City's eco-policies. After the lecture, a question and answer session is held. Students write a report about the lecture to deepen students' understanding of Toyota City's eco-policies.

\section{Week 4: Analysis of other environmental model cities in Japan}

Students review the wider literature on eco-cities in Japan (e.g., Kyoto, Toyama). Students prepare presentations about their findings for the fifth session.

\section{Week 5: Group presentation on other environmental model cities in Japan}

Students deliver group presentations based on the findings from their research about other eco-cities in Japan. As in the second session, students are assessed and given feedback about the presentation (e.g., content, structure) from their peers and instructor.

\section{Week 6: Environmental model cities around the world}

Based on the feedback received for the previous presentation, students work on making improvements to their presentations for the seventh week.

\section{Week 7: Group presentations on environmental model cities around the world}

Students perform group presentations about the themes outlined above. Presentations are again assessed by the students' peers and the instructor. 


\section{Week 8: Comparative analysis of environmental cities}

After a research methods tutorial and after clarifying the research topic and purpose (i.e., measuring Toyota citizens' awareness of the city's eco-policy), each team formulates five survey questions ( 25 questions in total). The instructor selects the most relevant questions for the research to take place in Toyota City. Each team then submits a report based on the previous presentations based on the key words associated with each theme (e.g., Ecoful Town, HEMS). Students are assessed individually, based on their written contribution, to increase individual accountability. These reports formed part of the literature review.

\section{Week 9: Guest lecture: Director of UNCRD}

In order to broaden student knowledge and understanding of eco-policies, the director of the United Nations Center for Regional Development (UNCRD), a UN agency engaged in sustainable regional development, gives a lecture about sustainable development at the global level.

\section{Week 10: Guest lecture: Personnel from JTB}

Personnel from the Japan Touristic Bureau (JTB), one of the largest travel agencies in Japan, which helped promote Toyota City's eco-policies, give a lecture about their professional experiences in marketing and research. A question and answer session is held between students and the personnel.

\section{Field research: Questionnaire research in Toyota City}

On the Saturday between the tenth and eleventh sessions, students conduct surveys in the Toyota City station area.

\section{Week 11: Analysis of collected data}

Students analyze and discuss the collected data. They submit preliminary analysis reports with recommendations to further improve citizens' recognition of Toyota City's eco-policy.

\section{Week 12: Analysis of collected data}

Students further analyze the data from different perspectives (e.g., comparing the data between teenagers and adults age twenty and above) and submit reports based on their findings. Suggestions are again made to promote awareness of the eco-policy. Students also create questions relevant to Toyota City's eco-policies for the final exam (e.g., What actions can we take to address the heat-island phenomenon?). Together, students and the instructor select the most relevant questions to be further elaborated.

\section{Week 13: Revisions of drafts}

Students work on the literature review and data analysis under the guidance of the instructor. They also complete a mock exam based on the questions selected from the previous week. They discuss possible answers with peers and the instructor. They self-assess their research skills using the evaluation sheets based on shakaijin kisoryoku (essential competencies for professionals).

\section{Week 14: Review and Assessment}

Students take the final exam and completed evaluation sheets to evaluate the course itself. The instructor reviews the course, addressing students' comments, and makes suggestions on how the course can be improved in the future. 